\title{
Assessment of Mycoremediation Potential of Fusarium Spp. On Polycyclic Aromatic Hydrocarbon in Western India
}

\author{
Sonam Gupta, Sera Fernandes, Hajra Gupta, Dr. Sejal Rathod
}

Department of Biotechnology, Kishinchand Chellaram College, Mumbai, Maharashtra, India

\begin{abstract}
Article Info

Volume 8, Issue 5

Page Number : 509-515

Publication Issue

September-October-2021

\section{Article History}

Accepted : 16 Oct 2021

Published : 30 Oct 2021

Motor or engine oil is a lubricant for engines containing majorly of base oils; these base oils include petrol-based hydrocarbons. Petroleum hydrocarbon contamination is one of the major environmental problems resulting from its large scale uses in transportation, industrial and other sectors. Accidental release and workshop seepage of petroleum products are the key concern of the environment. Fresh engine oil contains polycyclic aromatic hydrocarbons (PAHs). Used engine oil also leads to further generation of PAHs. As an attempt to clean up such hydrocarbons, bioremediation or biodegradation methods are adapted. Bioremediation is a cost effective and eco-friendly treatment for oil contaminated materials by the use of micro-organisms. The present study is an attempt to isolate and find out hydrocarbon degrading fungi from oil and petroleum contaminated regions. Biodegradation potential of soil mycobiota isolated from automobile mechanic workshop in Virar on engine oil was investigated using standard methods. The most capable oil degrading fungi was identified morphologically by wet mount technique as Fusarium sp. The biodegradation of hydrocarbons and oil was determined by using 2,6 Dichlorophenol-indophenol (DCPIP) assay and gravimetric analysis. The quantitative estimation of engine oil degradation showed rate of degradation as $87 \%$ and $89 \%$. This study confirms that isolated Fusarium sp. has the potential exploited in the bio-treatment and removal of hydrocarbons from the polluted soil. Results were recorded in the form of biodegradation percentage of hydrocarbon. The present study and their results can give unique future prospects in the field of bioremediation and biodegradation of petroleum contaminated soil.
\end{abstract}

Keywords : Bioremediation, Fusarium sp. DCPIP, Petroleum hydrocarbon, Gravimetric analysis. 


\section{INTRODUCTION}

Engine oil is a lubricant for engines containing majorly of base oils, which includes petroleum based hydrocarbons. Motor oil can have an incredibly damaging effect on the environment, particularly to plants that depend on healthy soil to grow. Petroleum hydrocarbons are released from petroleum industry as major waste product, which when released in environment destroys the natural flora and fauna of the region. Used engine oil leads to generation of more polycyclic aromatic hydrocarbons (PAHs) which too has devastating effect on environment [20]. The term polycyclic aromatic hydrocarbons (PAHs) also known as polynuclear aromatic hydrocarbons are a class of organic chemicals consisting of two or more fused aromatic rings and do not contain hetero atom or carry substitutes. PAHs belong to the group of persistent organic pollutants (POPs). These are organic pollutant contaminants that are resistant to degradation, can remain in environment for a long period and have the potential to cause adverse environmental effects. As a pollutant, they are at concern because some compounds have been identified as carcinogenic and mutagenic. PAHs are also present in oil, tar deposits and are even produced as a by-product of fuel burning [9].

The major environmental concern in urban and industrial areas with regard to polycyclic aromatic hydrocarbons is that they possess a relatively low solubility in water, affecting the aquatic ecosystem. Toxic effects of used oil on freshwater and marine organisms are significant long-term effects. Used motor-oil dumped on land reduces soil productivity. Improperly disposed used oil ends up in landfills, sewers, backyards, or storm drains where soil, groundwater and drinking water may become contaminated. Treating these contaminated sites using physio-chemical processes prove to be harmful for environment. Bioremediation can be opted for such treatment procedures. Bioremediation includes use of living organisms like microbes and plants, in the removal of contaminants, pollutants, and toxins from soil, water, and other environments. Mycoremediation involves using fungi to eliminate or remove contaminants or pollutants from the environment. Fungal bioremediation technology is highly efficient and versatile compared to that of protozoan or bacterial type, due to robust growth of fungus, vast hyphal network. Hence, mycoremediation can be an economical, ecofriendly, and effective strategy to combat the everincreasing problem of soil and water pollution. Robust growth of fungus, vast hyphal network, production of versatile extracellular lignolytic enzymes, high surface area to volume ratio, resistance to heavy metals, adaptability to fluctuating $\mathrm{pH}$ and temperature and presence of metal-binding proteins; fungi are an ideal candidate for the remediation of various pollutants [1].

The various fungi genera which have been proven to be effective degraders of engine oil and other PAHs include Aspergillus, Penicillium, Rhizopus, Fusarium, Mucor, etc [6]. Use of these fungi can be preferred in case of oil spills, contamination of land by PAHs and even in treatment of petroleum hydrocarbons which are released as major waste from petroleum industries. The present study aims at exploring efficacy of indigenous fungi as potential bioremediating agents in treating petroleum hydrocarbon contaminated soil and water. Following isolation and identification of a number of engine oil degrading fungi, the extent of degradation of engine oil by the isolates reveals their potentials in alleviating the devastating pollution through bioremediation. 


\section{MATERIALS AND METHODS}

\section{A. Sources of soil sample}

The two contaminated soil samples were collected from two automobile mechanical garages located in Virar, Maharashtra, India; where spillage of engine oil was common over the years.

Samples were collected from each site from just $1 \mathrm{~cm}$ below the soil surface and were transported to a laboratory in polythene bags and were kept in a refrigerator (in order to keep the organisms viable and free from any contamination) before analysis.

\section{B. Isolation of PAHs degrading fungi using enrichment media}

The collected soil sample was subjected to serial dilution $\left(10^{-1}-10^{-5}\right)$ and then spread plate method was employed. The last three dilutions $\left(10^{-3}-10^{-5}\right)$ were plated on PDA (Potato Dextrose Agar) medium, to which streptomycin was incorporated, so as to avoid contamination by bacteria, and the plates were incubated at $28^{\circ} \mathrm{C}$ for 7 days. The same soil samples were also subjected to enrichment of PAHs degrading fungi using PDA media. Sugar source was replaced with engine oil in the latter. The soil sample was added to $100 \mathrm{ml}$ PDB (Potato Dextrose Broth) supplemented with $2 \%$ engine oil as a carbon source [12]. Prior to adding engine oil, the media was sterilized by autoclaving at $121^{\circ} \mathrm{C}$ for 30 minutes. To this media streptomycin was added to avoid bacterial contamination. Both the flasks were incubated at $28^{\circ} \mathrm{C}$ on a rotary shaker at $180 \mathrm{rpm}$ for 7 days. The PDB consisted of engine oil as sole energy source and only mycoflora with biodegradation capacity present in the soil were allowed to flourish in the enrichment media.

After 7 days of incubation, PDA plates were prepared containing $2 \mathrm{ml}$ engine oil and streptomycin. In both the plates $1 \mathrm{ml}$ of culture from the incubated flasks were added, and spread plate method was employed. Plates were incubated at room temperature (RT) for 7 days. To observe the growth pattern of the fungi, the colonies were also inoculated on Sabourauds dextrose agar (SDA).

\section{Characterization of fungal isolates}

The fungal isolates were characterized based on their macroscopic and microscopic features.

Colonies from the fungal plate were transferred aseptically to a sterile slide with the help of a sterile forceps. A pure culture of the fungal isolate was flooded with a few drops of lactophenol cotton blue stain and covered with a fresh coverslip. Both were thereafter viewed under X10 and X40 objective lens.

\section{Preliminary screening for confirming biodegradation potential of fungal isolates}

MSM (Mineral Salt Medium) $100 \mathrm{ml}$ along with $2 \%$, $5 \%, 10 \%(\mathrm{v} / \mathrm{v})$ engine oil in Erlenmeyer flasks were used for the biodegradation experiments. The preliminary screening test involved MSM media along with modified DCPIP (2,6Dichlorophenolindophenol) method to estimate the degradation capacity of fungal isolates [2]. For this, MSM was sterilized by autoclaving at $121^{\circ} \mathrm{C}$ for 30 minutes before addition of engine oil. 5 agar plugs from the growing edges of the fungal-colonized PDA with the aid of a sterile cork-borer of $5 \mathrm{~mm}$ diameter, and inoculated in this degradation media supplemented with $0.4 \mu / \mathrm{ml}$ of DCPIP and incubated at RT for 14 days in constant shaking conditions. The decolorization of DCPIP from (deep blue to colourless) indicated engine oil degradation capacity of the fungal isolates.

\section{E. Estimation of petroleum hydrocarbon degradation by gravimetric analysis}

The estimation of biodegradation ability of fungal strains was done and rate of degradation was expressed in percent degradation. The modified MSM which consisted of $5 \%$ engine oil was used to grow fungal isolates. For this, 5 plugs of $5 \mathrm{~mm}$ diameter from PDA were inoculated in MSM with $5 \mathrm{ml}$ of oil and then incubated at $28 \pm 1^{\circ} \mathrm{C}$ for 7 days on rotary 
shaker. Following 7 days cell free culture broth was obtained through filtration and centrifugation. Further the engine oil fraction was extracted from this cell free culture broth with three volumes of toluene using separating funnel. Aqueous and organic layers were formed. The optical density was measured at $420 \mathrm{~nm}$ by $\mathrm{UV}$ visible spectrophotometer. The degradation percentage was calculated using the equation: Degradation $\%=\mathrm{C}_{0}-\mathrm{C} / \mathrm{C}_{0} \times 100$, where $\mathrm{C}_{0}$ and $\mathrm{C}$ refer to initial and final concentration respectively [7].

\section{RESULTS AND DISCUSSION}

\section{A. RESULTS}

\section{Isolation of engine oil degrading fungi using enrichment media}

As the soil samples were serially diluted and then plated on sterile PDA medium, a number of fungi colonies irrespective of their ability to degrade engine oil grew on the petriplates. Whereas in case of soil sample subjected to enrichment media (PDB with $2 \%$ engine oil) growth of few fungal isolates were observed; only those which had the ability to utilize engine oil. Total 2 fungi were isolated by using modified PDA medium (which composed of 2\% engine oil as carbon source).

\section{Characterization and identification of fungal isolates}

On PDA plates colonies were fast growing with white to cream aerial and substrate mycelium. On SDA the colonies appeared white and red pigment production was observed. Lacto phenol cotton blue staining agent was applied for microscopic identification of fungal isolates. From microscopic observation it was identified as filamentous fungi. Morphological characteristics of strains, including their conidiophores, were compared with those of the known species of fungi. This revealed that the fungi exhibited both macro and microconidia. Microconidia were oval. Macroconidia were oval, tapering and septated in 2 cells. Macro-conidia, elongated, gently to strongly curve with somewhat pointed ends. Microconidia which had conidiogenous cells were thicker than vegetative hyphae; which were with terminal or intercalary chlamydospores (thick- walled spore-like swellings of vegetative cells). The microscopic characterization of isolated fungi were inferred from mycology manual, and were identified to be of Fusarium spp.
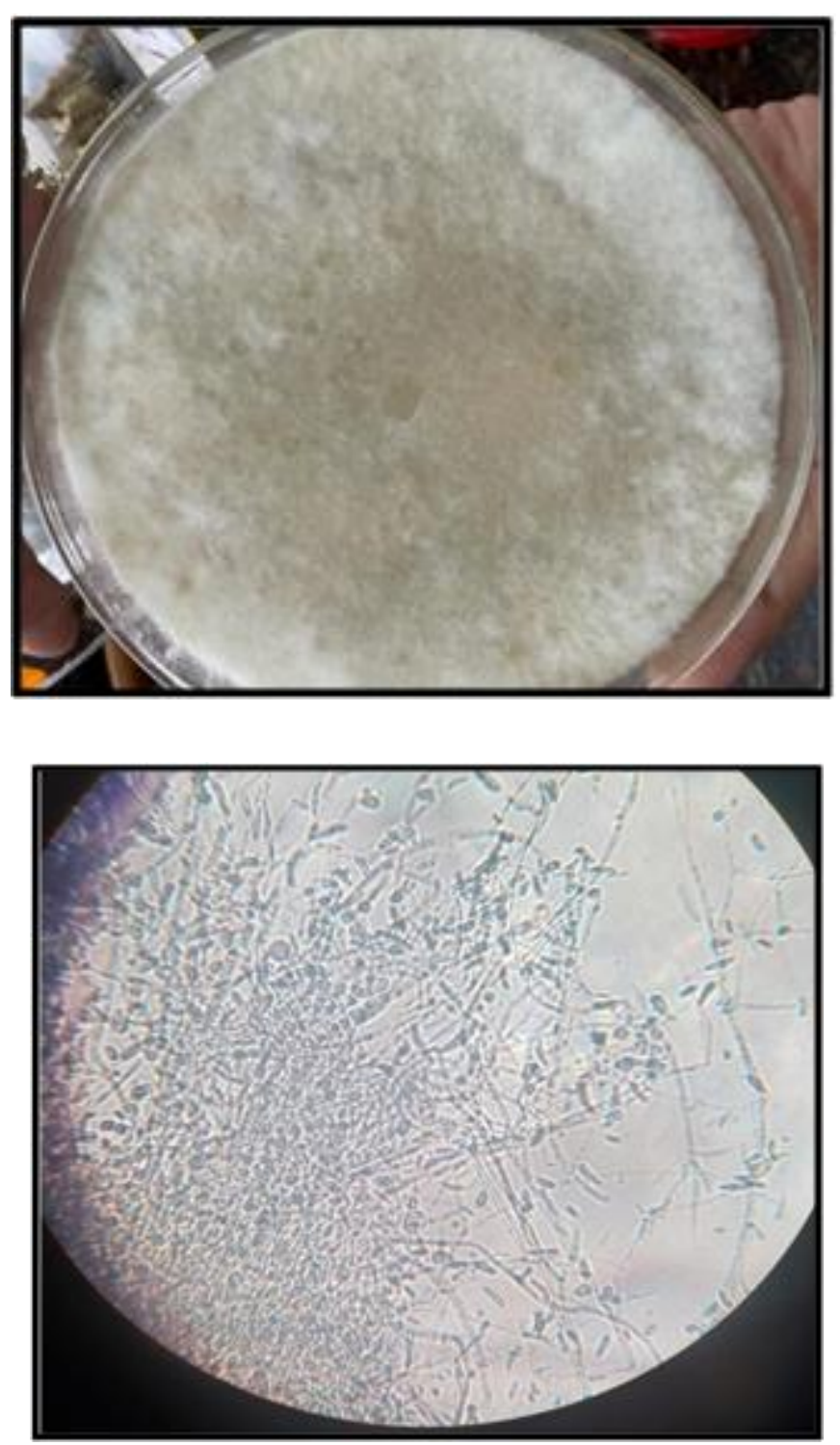

Figure 1: (Left to Right) Enriched fungal isolate on petroleum containing media and microscopic identification of fungus 


\section{Preliminary screening for confirming} biodegradation potential of fungal isolates by DCPIP assay

5 discs of agar plugs from PDA plates were inoculated into flasks containing $100 \mathrm{~mL}$ of MSM supplemented with $40 \mu \mathrm{g} / 100 \mathrm{~mL}$ of redox indicator (2,6-DCPIP) and different concentrations of engine oil such as $2 \%$, $5 \%, 10 \%(\mathrm{v} / \mathrm{v})$. The cultures were incubated at $28 \pm 1^{\circ} \mathrm{C}$ for 14 days in constant shaking conditions. Control flasks were also prepared which constituted of MSM media with engine oil. The flasks were observed daily for color change. Change in the color of the inoculated degradation medium from deep blue to colorless indicated the capability of the fungi to degrade engine oil. The mechanism used by fungi to biodegrade engine oil was observed by incorporating an electron acceptor, i.e. DCPIP. This result indicated that the two fungi had the capability to degrade crude oil.
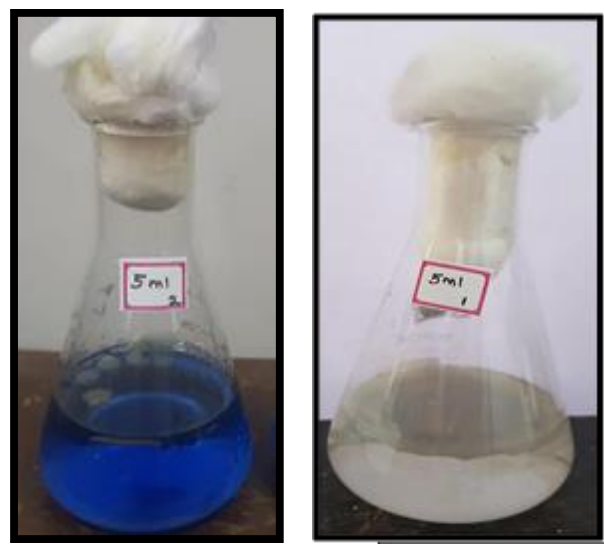

Figure 2: DCPIP redox reaction in fungal isolate (MSM with 5\% engine oil)

\begin{tabular}{|c|c|}
\hline $\begin{array}{c}\text { \% Engine } \\
\text { Oil }\end{array}$ & Blue to Colorless \\
\hline $2 \%$ & Day 8 \\
\hline $5 \%$ & Day 11 \\
\hline $10 \%$ & Day 13 \\
\hline
\end{tabular}

Table 1 : Color change observations
4. Quantitative estimation of engine oil degradation using gravimetric analysis

To note the oil degradation; after 7 days of incubation in MSM containing 5\%of engine oil estimation of oil degradation was done gravimetrically. For this, the cell free culture broth was extracted with three volumes of toluene using separating funnel. The optical density of oil layer of both samples and control were measured as follows at $420 \mathrm{~nm}$.

The rate of degradation or percentage degradation was calculated using the formula: Degradation (\%) = $\left(\mathrm{C}_{0}-\mathrm{C}\right) / \mathrm{C}_{0} \times 100$, where $\mathrm{C}_{0}$ and $\mathrm{C}$ refers to initial and final concentration of extracted engine oil, respectively. Both fungi proved to be efficient in petroleum hydrocarbon degradation.

\begin{tabular}{|c|c|c|c|}
\hline Sr No. & Aliquots & O.D & \% Degradation \\
\hline 1 & Control & 1.76 & 0.00 \\
\hline 2 & Sample 1 & 0.22 & 87 \\
\hline 3 & Sample 2 & 0.19 & 89 \\
\hline
\end{tabular}

Table 2 : O. D. of control and samples

\section{B. DISCUSSION}

Petroleum based hydrocarbon and polycyclic aromatic hydrocarbons (PAHs) contamination is increasing due to anthropogenic activities. Potato Dextrose Agar (PDA) \& SDA were used for isolation, cultural and morphological characterization of fungi. However, Czapek Dox Agar (CDA) media has been also used for morphological characterization of fungus along with PDA [7]. MSM and Bacto Bushnell- Haas broth (BHB) are widely used in quantitative and qualitative analysis of biodegradation experiments for maintenance of fungal isolates [8] [19] [1].

Among fungal bioremediating agents, common mold species of Mucor, Rhizopus, Aspergillus, Curvularia, 
Fusarium, Penicillium, Trichoderma and Lasiodiplodia, have been recognized in hydrocarbon degradation and its derivatives [4].

Sandhu, S. S., et al, determined the biodegradation of hydrocarbons and oil by Diethyl ether analysis and Spectrophotometrically [12].

The various enzymes of fungi implicated in the PAHs degradation are laccase, lignin and manganese peroxidase [3][4]. In the present study, the extent of degradation was evaluated by measuring the optical density (O. D). The gas chromatography analysis on PAHs degradation before and after treatment with fungal isolates exhibits biodegradation efficiency and also confirms their high degradation potentials, which have been employed by Chukwura, et al. [6]

High biodegradation efficiency was (>80\%) exhibited by Fusarium spp. The similar results of our study were also obtained by Chukwura et al., [6] in their studies [6].

The present study revealed the potential of Fusarium, fungal species in bioremediation of PAHs contaminated sites.

\section{CONCLUSION}

The study revealed that engine oil degrading indigenous mycobiota could be isolated from soil of automobile workshop contaminated with engine oil; using modified PDA (with $2 \%$ engine oil) as enrichment media. These fungal isolates indicated their ability to degrade engine oil in the degradation media that is, modified MSM (containing 2\% engine oil) where, fungi utilized engine oil as sole energy and carbon source. The microscopic characteristics of fungal isolates were recorded and it showed presence of macro and micro-conidia, which are distinct features of fungi belonging to Fusarium genera. Hence fungal isolates were identified to be of Fusarium species. Through screening analysis it was indicated that the isolated fungal colonies had the capability in degradation of $2 \%, 5 \%$ and $10 \%$ engine oil concentrations. The isolates rapidly utilized the engine oil before the incubation period of 14 days. The estimation of rate of engine oil degradation was calculated to be $87 \%$ and $89 \%$. This study thereupon revealed about great capability of isolated Fusarium species in degradation of petroleum based hydrocarbons. There exists quite a possibility that more number of fungal isolates would have been identified, if more number of soil samples would have been collected. Also, the time of sample collection might have affected the number and the type of fungus species isolated. The enzymatic mechanisms followed by Fusarium spp for degradation of PAHs, can further be evaluated.

\section{ACKNOWLEDGEMENT}

The authors would like to extend their deepest and sincere gratitude to the DBT Star Status grant, Jigyaasa- Science Honors Program and Kishinchand Chellaram College, Mumbai for providing this opportunity and well equipped laboratory to complete this research.

\section{REFERENCES}

[1]. Akhtar, N., \& Mannan, M. A. U. (2020). Mycoremediation: Expunging environmental pollutants. Biotechnology Reports, e00452, 2215017X.

[2]. Al-Hawash, A. B., Alkooranee, J. T., Abbood, H. A., Zhang, J., Sun, J., Zhang, X., \& Ma, F. (2018). Isolation and characterization of two crude oildegrading fungi strains from Rumaila oil field, Iraq. Biotechnology reports, 17, 104-109.

[3]. Al-Hawash, A. B., Alkooranee, J. T., Zhang, X., \& Ma, F. (2018). Fungal degradation of polycyclic aromatic hydrocarbons. Int J Pure App Biosci, 6(2), 8- 24.

[4]. Balaji, V., Arulazhagan, P., \& Ebenezer, P. (2014). Enzymatic bioremediation of polyaromatic 
hydrocarbons by fungal consortia enriched from petroleum contaminated soil and oil seeds. Journal of Environmental Biology, 35(3), 521- 529.

[5]. Chaudhry, S., Luhach, J., Sharma, V., \& Sharma, C. (2012). Assessment of diesel degrading potential of fungal isolates from sludge contaminated soil of petroleum refinery, Haryana. Research Journal of Microbiology, 7(3), 182.

[6]. Chukwura, E. I., Ojiegbu, N. M., \& Nwankwegu, A. S. (2016). Hydrocarbon degradation potentials of fungi associated with oil-contaminated soil from selected mechanic workshops in Awka, Anambra State, Nigeria. Frontiers in Environmental Microbiology, 2(6), 38-44.

[7]. Dhar, K., Dutta, S., \& Anwar, M. N. (2014). Biodegradation of petroleum hydrocarbon by indigenous fungi isolated from ship breaking yards of Bangladesh. International Research Journal of Biological Sciences, 3(9), 22-30.

[8]. Ghosal, D., Ghosh, S., Dutta, T. K., \& Ahn, Y. (2016). Current state of knowledge in microbial degradation of polycyclic aromatic hydrocarbons (PAHs): a review. Frontiers in microbiology, 7, 1369.

[9]. Igwe, J. C., \& Ukaogo, P. O. (2015). Environmental effects of polycyclic aromatic hydrocarbons. Journal of Natural Sciences Research, 5(7), 117-132.

[10]. Khan, S. R., Ji, N. K., Kumar, R. N., \& Patel, J. G. (2015). In vitro study on assessment of petrol, kerosene and diesel degrading potential of indigenous fungal isolates from different petroleum product effected soils. International Journal of Recent Research and Review, 8(1), 8-15.

[11]. Romauld, S. I., Venkataraghavan, R., Yuvaraj, D., Devi, V. I., \& Hashika, S. (2019). Mycoremediation of Hydrocarbon and its products using Fusarium oxysporum. Research Journal of Pharmacy and Technology, 12(9), 4216-4224.

[12]. Sandhu, S. S., Shakya, M., Deshmukh, L., Aharwal, R. P., \& Kumar, S. (2016). Determination of hydrocarbon degrading potentiality of indigenous fungal isolates. International Journal of Environmental Sciences, 6(6), 1163-1172.

[13]. Batelle, C. D. (2000). Mushrooms: Higher Macrofungi to clean up the environment. Environmental Issues, Fall.
[14]. Cerniglia, C. E. (1984). Microbial metabolism of polycyclic aromatic hydrocarbons. Advances in applied microbiology, 30, 31-71.

[15]. Cerniglia, C. E. (1992). Biodegradation of polycyclic aromatic hydrocarbons. Biodegradation, 3(2-3), 351-368.

[16]. Chapelle, F. H. (1995). Bioremediation: Nature's way to a cleaner environment (No. 054-95). US Geological Survey.

[17]. Chaudhry, S., Luhach, J., Sharma, V., \& Sharma, C. (2012). Assessment of diesel degrading potential of fungal isolates from sludge contaminated soil of petroleum refinery, Haryana. Research Journal of Microbiology, 7(3), 182.

[18]. Ghosal, D., Ghosh, S., Dutta, T. K., \& Ahn, Y. (2016). Current state of knowledge in microbial degradation of polycyclic aromatic hydrocarbons (PAHs): a review. Frontiers in microbiology, 7, 1369.

[19]. Khan, S. R., Ji, N. K., Kumar, R. N., \& Patel, J. G. (2015). In vitro study on assessment of petrol, kerosene and diesel degrading potential of indigenous fungal isolates from different petroleum product effected soils. International Journal of Recent Research and Review, 8(1), 8-15.

[20]. Behera, B. K., Das, A., Sarkar, D. J., Weerathunge, P., Parida, P. K., Das, B. K., \& Bansal, V. (2018). Polycyclic Aromatic Hydrocarbons (PAHs) in inland aquatic ecosystems: Perils and remedies through biosensors and bioremediation. Environmental pollution, 241, 212-233.

\section{Cite this article as :}

Sonam Gupta, Sera Fernandes, Hajra Gupta, Dr. Sejal Rathod, "Assessment of Mycoremediation Potential of Fusarium Spp. On Polycyclic Aromatic Hydrocarbon in Western India", International Journal of Scientific Research in Science and Technology (IJSRST), Online ISSN : 2395602X, Print ISSN : 2395-6011, Volume 8 Issue 5, pp. 509515, September-October 2021. Available at doi : https://doi.org/10.32628/IJSRST218571 Journal URL : https://ijsrst.com/IJSRST218571 